The nostalgic logos in sor Juana Ines de la Cruz

\title{
El logos nostálgico en sor Juana Inés de la Cruz
}

Enrique Rodríguez Martín del Campo

Universidad Autónoma de Madrid. enrique.rm55@gmail.com

DOI: http://dx.doi.org/10.15366/bp2018.18.014

Bajo Palabra. II Época. No18. Pgs: 291-304

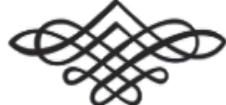


Recibido: 10/12/2016

Aprobado: 29/07/2018

\section{Resumen}

Debido a su complejidad y a la profundidad temática qué hay en sus versos y en su prosa, la obra de sor Juana Inés de la Cruz ha sido objeto de cuidadosos estudios que resaltan su indiscutible valor intelectual. No obstante, la mayoría de estos estudios distinguen el aspecto especulativo y estilístico de su obra. Por lo cual, este trabajo pretende arrojar luz sobre algunos elementos que destacan el acento más personal o íntimo de la monja Jerónima para perfilar su personalidad y, a su vez, mirar su obra desde un ángulo alternativo. Sin embargo, no es la intención descontextualizar la obra de Sor Juana y oponer una perspectiva contraria a la poética barroca, que se caracteriza por su complejidad y su lógica interna, sino señalar algunos aspectos de sus preocupaciones y deseos personales que, sin duda, están plasmados en sus escritos y aportan una mayor riqueza al estudio de su obra.

Palabras clave: barroco, nostalgia, sueño, poesía, emociones, amor, religión.

\section{Abstract}

Due to its complexity and the thematic depth in its verses and in its prose, the work of Sor Juana Ines de la Cruz has been the object of careful studies that accentuate its indisputable intellectual value. Nevertheless, most of these studies distinguish the speculative and stylistic aspect of her work. Therefore, this work aims to shed light on some elements that highlight the most personal or intimate accent of the Jeronim nun to outline her personality and, in turn, look at her work from an alternative angle. However, it is not the intention to decontextualize the work of Sor Juana and to oppose a perspective contrary to the baroque poetics, which is characterized by its complexity and its internal logic, but rather to point out some aspect of her personal concerns and desires that are undoubtedly embodied in her writings and bring greater wealth to the study of her work.

Keywords: baroque, nostalgia (homesickness), dream, poetry, emotions, love, religión. 
En dos partes dividida tengo el alma en confusión: una, esclava a la pasión, y otra, a la razón medida. Guerra civil, encendida, aflige el pecho importuna: quiere vencer cada una, y entre fortunas tan varias morirán ambas contrarias, pero vencerá ninguna.

Sor Juana Inés de la Cruz

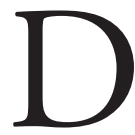
e acuerdo con José Pascual Buxó, pese a la certidumbre popular que asume que la expresión poética guarda una carga emocional y personal del propio autor, no es posible decir que pertenezca por entero a éste, pues tanto la palabra como el deseo se encuentran en un plexo de eslabones constituidos por la tradición ideológica, es decir, se gestan en un contexto que, en cierta forma, también los determina e, incluso, los demanda. En el caso de Sor Juana, si sólo atendemos aquella aserción donde asegura no haber escrito nada por su gusto, de no ser el Primero sueño,${ }^{1}$ la consigna de Buxó se certifica.

Diego Calleja, biógrafo de la Décima musa, afirma que aquellos versos que desbordan "graves agonías por lograr un devaneo", son versos de amor que Sor Juana escribe "sin amor", en tanto que sólo conocía tal sentimiento de manera teórica, por las relaciones codificadas y solemnes que atestiguó en la corte virreinal. De igual forma, Octavio Paz advierte ${ }^{2}$ sobre el equivoco de leer en los textos poéticos sorjuaninos halos de romanticismo, pues ello implicaría descontextualizar a la monja jerónima y malinterpretar su obra. No obstante, si atendemos a la propuesta de Ezequiel Adeodato Chávez en su Ensayo de psicología de Sor Juana Inés de la Cruz, nos dice que en cada una de las composiciones de la Fénix de México escapan gritos de su yo más íntimo, lo cual, considerando el contexto en el que se desarrolló el barroco novohispano, no es desatinado. ${ }^{3}$ Esta opinión, en modo alguno, la comparten Ludwig Pfandl y Rubén Salazar Mallén, en sus destacados estudios sobre la poetisa.

\footnotetext{
${ }^{1}$ Cruz, Sor Juana InÉs de la, Respuesta de la poetisa a la muy ilustre Sor Filotea de la Cruz, en: Polémica, Mirla Alcibíades (ed.), Biblioteca Ayacucho, Caracas, 2004, p. 105.

2 Véase Paz, Octavio, Sor Juana Inés de la Cruz o las trampas de la fe, FCE, México, 1982.

3 Cf. Ezequiel A. Chávez, Ensayo de psicología de Sor Juana Inés de la Cruz y de estimación del sentido de su obra y de su vida para la historia de la cultura y de la formación de México, Editado por la Asociación Civil Ezequiel A. Chávez, México, 1972, p. 43.
} 
Dicha cuestión ha suscitado una gran polémica que no se ha podido zanjar, debido a que Sor Juana nunca quiso revelar expresamente su universo interior y por ello torció muchas veces sus palabras y llegó a firmar con el pseudónimo de Julia. De ahí que el carácter más estudiado y enfilado en su obra haya sido el circunspecto y reflexivo.

Esta exposición es tan sólo un modesto trazo que pretende arrojar luz sobre esa parte que no se puede soslayar, a saber: la vida interior de Sor Juana, a través de algunos fragmentos de su vida y obra para identificar sus más hondas preocupaciones, tanto especulativas como morales. Consignar tales rasgos es una tarea intrincada, no obstante, para aproximarnos de una manera más o menos objetiva al conocimiento de su personalidad, es menester acudir a tres textos básicos:

1. Las notas biográficas que sobre Juana Inés escribió Diego Calleja, amigo íntimo de Sor Juana, y a las que autores como Alfonso Méndez Plancarte y Antonio Alatorre acuden para afianzar sus obras. ${ }^{4}$

2. La Respuesta de la poetisa a la muy ilustre Sor Filotea de la Cruz, que la Fénix de México escribió en 1691.

3. La Carta de la madre Juana Inés de la Cruz escrita al Padre Antonio Núnez, de la Compañia de Jesús, escrita en 1682.

Sin embargo, quedan muchos cabos sueltos, como: la importancia que tuvo para ella el saberse hija ilegítima — situación que intentó ocultar por mucho tiempo-, el rotundo motivo que la llevó a abandonar la corte de los virreyes para refugiarse en el convento, el saber si vivió o no un profundo amor como el que describe en sus poesías y, quizás el más importante: la causa de su repentina conversión y el abandono de la actividad intelectual. Así pues, es menester continuar indagando en su obra y en sus contextos para abrir líneas interpretativas, igualmente fiables, sobre estas cuestiones no menos importantes para la historia, la cultura y, por supuesto, para la filosofía.

\section{Juana Inés de Asuaje y sus entornos}

El PROCESO DE COLONIZACión en MÉXico, señalado por la introducción de nuevas estructuras políticas, sociales y culturales, generó de forma sucesiva un ambiente

\footnotetext{
${ }^{4}$ Ambos autores realizan interesantes estudios y ofrecen grandes aportaciones en la introducción a las Obras Completas de Sor Juana Inés de la Cruz, editadas por el FCE, México, 1997 y 1999.
} 
de desconcierto y angustia existencial que dio lugar a nuevas formas de percibir la realidad y, por ende, a una nueva conciencia. De este sentimiento de ofuscación participaron igualmente los conquistadores, los indígenas y los criollos. Por una parte, los conquistadores, si bien contemplaron su empresa con los ánimos propios de la modernidad occidental, también es cierto que permanecían sujetos a las ideas y a los valores del medioevo, de manera que no gozaban de plena autonomía. Por otra parte, los precolombinos, se sentían usurpados, amputados de sus creencias y lacerados en sus valores. Finalmente, los criollos, miraban con gran turbación su circunstancia al no pertenecer a ningún estamento en la sociedad y, por ende, carecían de una identidad auténtica. De aquí que sea posible enmarcar un problema ontológico y axiológico que merece la pena atender y analizar cuidadosamente en estudios específicos.

Aunado a esto, en las comunidades religiosas de la colonia surgieron enfrentamientos entre los frailes criollos y peninsulares que cuestionaban o apoyaban la conservación del régimen moral e intelectual de la escolástica decadente en que vivían. Para mitigar la tensión entre los frailes, el Papa Urbano VIII emitió un decreto que ordenaba la alternancia de los sacerdotes criollos y peninsulares en los altos cargos de las iglesias. Sin embargo, en la práctica, la frecuente omisión de tal decreto desencadenó conflictos importantes que darían lugar a movimientos mayúsculos de sublevación, que más tarde repercutieron en los ámbitos político, económico, social y cultural. ${ }^{5}$

En este embrollado entorno, trazado por el sentimiento de desamparo, el anhelo de concordia política y social y la inquietud por alcanzar un mayor discernimiento al estilo de la modernidad occidental, se desarrolló el barroco novohispano, que, en tanto inclinación artística, al no tener que apoyarse en una sola tendencia: "abjura de los modos del pasado inmediato, más aún, pretende desasirse de la historia." ${ }^{6}$ Por ello, se trata de un arte excéntrico, en comparación con el románico, el gótico o el renacentista, que apuntaban a exaltar características determinadas y, por ende, apoyados siempre en la formalidad. El barroco novohispano, en cambio, es un arte que pudo valerse de cualquier argucia técnica, ya que no que no se ciñó a ninguna finalidad ajena a sí mismo. En él se conjugaban emociones e intenciones diversas, pues también se manifestó como el intento de establecer una modernidad alternativa al movimiento reformista, o como la denuncia de la falta de coherencia en el capitalismo, por citar algunos ejemplos. De aquí que se pueda corroborar que el

\footnotetext{
5 Véase Gallegos Rocafull, José María, El pensamiento mexicano en los siglos XVI y XVII, Ediciones del IV Centenario de la UNAM, México, 1951, pp. 105 y ss.

${ }^{6}$ Ruíz, Beatriz, "Una idea sobre el barroco en México”, en: Peña, Margarita (comp.), Cuadernos de Sor Juana, Coordinación de Difusión Cultural UNAM, México, 1995, p. 365.
} 
barroco novohispano es un arte que también expresa una actitud, una necesidad de llenar vacíos. ${ }^{7}$

En este difícil entorno de incertidumbre y descontento, llegó al mundo Juana de Asuaje y Ramírez que, tras descubrir en Chimalhuacán el acta de bautismo, la mayoría de los críticos aceptan que nació el 12 de noviembre de 1648 en San Miguel Nepantla. ${ }^{8}$ Desde sus primeros ańos, como ella misma confiesa en su famosa Respuesta, tuvo un feroz apremio por acercarse a la lectura, pues, en modo alguno, sospechaba que los textos documentados podían mitigar la sed de curiosidad que le impelía a descubrir lo que a simple vista, pese a ser cotidiano, le parecía indescifrable. Señala, pues, con precisión, que no habiendo cumplido los tres años de edad, solía acompañar a su hermana mayor a que la enseñaran a leer, fue justo ahí donde sintió ese enorme deseo de encausarse en las letras. ${ }^{9}$ Y luego, recordando los años que pasó en la Panoaya, hacienda de sus abuelo, ratifica: "despiqué [sic] el deseo en leer muchos libros varios que tenía mi abuelo, sin que bastasen castigos ni reprensiones a estorbarlo." 10

En esta confesión es posible reconocer una actitud de incertidumbre y de fascinación, que son dos rasgos característicos del preludio filosófico, y dado que Juana Inés se acercó ávidamente a la lectura para descubrir aquello que "tenía que decirse" a través de la pluma, es innegable su disposición filosófica, signada por un logos, una razón o una capacidad intelectual inflamada en dudas que quería atenuar. Desde entonces se dispuso a la tarea de "estudiar para ignorar menos", ${ }^{11}$ a tal punto que dejó de comer queso por haber escuchado que provocaba rudeza o, mejor dicho, torpeza. ${ }^{12}$

Aprendió gramática en veinte lecciones y después manifestó su idea de asistir a la Universidad para cultivarse en el saber científico, materia por la que sentía gran

\footnotetext{
${ }^{7}$ Cf. Ibid., p. 369. De acuerdo con Beatriz Ruíz, las cascadas de oro que bañan la madera en las iglesias barrocas novohispanas, son una muestra de lo propiamente mexicano, pues si bien los detalles y los ornamentos que caracterizan a este arte tenían la función de exaltar los valores cristianos, también mostraban la riqueza natural que había en las minas de aquellas grandes y enigmáticas comarcas. Era, igualmente, una forma de gritar la necesidad que se tenía de Dios. Asimismo, el barroco, también se manifestó en otras disciplinas y técnicas del México colonial, como la gastronomía y la confección, pues en la primera se crearon guisos con más de 30 ingredientes, la dulcería conventual utilizaba distintas formas y colores llamativos, lo cual no era nada común; mientras que las indumentarias tradicionales se desbordaban en adornos e igualmente en colores.

${ }^{8}$ Existen desacuerdos sobre la fecha de nacimiento de Juana de Asuaje, pues Georgina Sabat de Rivers y Alejandro Soriano Vallés sostienen que el ańo exacto oscila entre 1651 y 1652, dado que no hay pruebas suficientes que atestigüen que el acta de bautismo es legítima, por el contrario, presenta inconsistencias, pues sostienen que Juana no utilizó el nombre de Inés sino hasta que ingresó al convento y que, además, tuvo una hermana en marzo de 1649. Véase Soriano Valles, Alejandro, Aquella Fénix más rara. Una historia del alma en la que se enfrenta la vanidad intelectual con la humildad ante Dios. Grupo Editorial Patria, México, 2000.

9 Véase Cruz, Sor Juana InÉs De La, Respuesta de la poetisa a la muy ilustre Sor Filotea de la Cruz, en: Polémica, op. cit., p. 78.

${ }^{10}$ Idem.

${ }^{11}$ Véase Ibid., p. 102.

12 Véase Ibid., pp. 78-79.
} 
interés, pero al ver reprimida esa intención, y en plenos años mozos hacia 1664, inició su etapa en la corte como dama de la virreina, donde al poco tiempo se ganó la admiración y el aprecio de los marqueses de Mancera, que quedaron atónitos ante la suntuosidad de su intelecto, y para quienes la joven poetisa compuso hermosos veros. Y así hasta 1667, en donde al no tener más futuro como dama de la corte — pues los virreyes eran sustituidos frecuentemente—, además su negativa a someterse a la voluntad de un marido, y sin medios económicos propios — dado que no era heredera de ninguna fortuna y en el siglo XVII no era permitido que la mujer se empleara en asuntos que no fueran los de su hogar-, no tuvo más opción que tomar los hábitos, pues como ella lo menciona: "era lo menos desproporcionado y lo más decente que podía elegir en materia de la seguridad que deseaba de mi salvación" ${ }^{13}$ Ingresó primero al convento de las carmelitas descalzas, pero sólo vivió ahí tres meses porque se dice cayó enferma. Posteriormente se integró al convento de San Jerónimo, al que perteneció toda su vida, donde desarrolló intensamente su labor intelectual, que le concedió excelsos honores y fama pero también muchas penas y quizá enemigos. Quizá esto último fue lo que la llevó a soltar la pluma y renunciar secamente a su empresa intelectual.

Sobre el final de su vida existen distintas versiones. La oficial, apoyada en Calleja, sostiene que murió cuando la peste entró en el convento de San Jerónimo en abril de 1695, pero autores como Antonio Alatorre y Elías Trabulse sostienen que se suicidó, el primero, y que fue asesinada, el segundo. ${ }^{14}$

\section{Sor Juana: El amor al conocimiento, la teología y el método del sueño}

En la testificación de su RESPUESTA, Sor Juana corrobora cuán vehemente fue el apetito de conocimiento que la llevó a la vida conventual, pues incluso creyó que

\footnotetext{
13 Ibid., p. 79.

${ }^{14}$ Elías Tarbulse contradice la exégesis de Calleja y asegura que de haber muerto Sor Juana por una epidemia, la población del convento hubiera disminuido de forma descomunal, lo cual, de acuerdo a sus indagaciones, no sucedió. Se ha dicho también que, al no contar ya con el respaldo de amigos influyentes ni con la asistencia de la corte, la poetisa se quedó completamente sola a expensas de las vejaciones de la iglesia, que se había volcado sobre ella, de manera que no tuvo más remedio que transigir y convertirse en la contadora del convento, pues de esa manera sabía que podía protegerse de los embates de sus enemigos, pero esta situación la tenía en una intranquilidad profunda, que más tarde la llevó al suicidio. Esta hipótesis la defiende el sorjuanista Antonio Alatorre, quien notó en la actitud de la Fénix un total abatimiento al verse privada de sus libros, de sus cosas personales y, sobre todo, de su pluma. En esas condiciones, según Alatorre, cualquier autor moderno, como lo fue nuestra poetisa, no puede pensar en otra cosa que no sea la enorme urgencia de morir. Finalmente, la opinión de Elías Trabulse es que Sor Juana fue asesinada, pues para él no es extraño deducir que el exceso de autoridad de la iglesia novohispana desapareció a varios personajes incómodos, entre ellos, por supuesto, a la autora barroca. Véase Trasbulse, Elías, La muerte de Sor Juana, Centro de Estudios de Historia de México, México, 1999.
} 
el aislamiento "voluntario" podría sosegar ese feroz ímpetu que no la abandonaba y que, en modo alguno, le afligía.

Pensé yo que huía de mí misma, pero ¡miserable de mí! trájeme a mí conmigo y traje mi mayor enemigo en esta inclinación, que no sé determinar si por prenda o castigo me dio el cielo, pues de apagarse o embarazarse con tanto ejercicio que la religión tiene, reventaba como pólvora, y se verificaba en mí el privatio est causa appetitus. ${ }^{15}$

Ciertamente, el claustro fue una válvula de escape que le permitió desarrollar su actividad intelectual, pero tampoco se puede omitir que la poetisa fue, al mismo tiempo, una mujer de una profunda convicción religiosa, adosada a algunos principios de la fe cristiana. En su obra, hay elementos e imágenes que no dejan de lado la vivencia de valores como la humildad, la caridad, el amor a Dios, los desposorios y la unión transformante del alma con Cristo entre otros aspectos.

Sin embargo, paradójicamente a ello, sus cuidadosas observaciones le permitieron notar que existe una apreciable diferencia entre la fe y el conocimiento, puesto que a nuestra autora no le interesó auspiciar con la razón las creencias religiosas ni los dogmas del credo católico, como fue el principal quehacer de los escolásticos medievales, ya que para la poetisa era evidente el orden distinto al que cada uno de estos ámbitos pertenecía. Más aún, en este rubro, Sor Juana fue más lejos que cualquier mujer de su época y homologó a la fe con ignorancia. De aquí se sigue que la razón —y por ende la filosofía - no tiene por que ser más una ancilla de la teología, sino que queda emancipada y sin la responsabilidad de dar amparo a la fe, tal como lo pretendieron los grandes intelectuales modernos en Occidente.

Asimismo, en la polémica Carta atenagórica, Sor Juana apunta a un aspecto que la centra en un humanismo, en tanto que libera al hombre de la dependencia absoluta de Dios para entregarle su propia potestad. En un primer momento, la autora sigue las instancias del credo católico, pero sus tesis sobre los beneficios negativos, la distancia radicalmente de la ortodoxia. Sostiene la poetisa que: "La mayor fineza del Divino Amor, en mi sentir, son los beneficios que nos deja de hacer por nuestra ingratitud" 16 Esto es así porque al haber una distancia sustancial y ciclópea entre Dios y el ser humano, la única forma en que éste puede responder a Dios es a través de la ingratitud y de la indiferencia, pues no hay que olvidar que es un ser efímero, lleno de flaquezas, que no son perniciosas ni deshonrosas, sino que simplemente lo definen y le impiden ir más allá de sus limitaciones, como lo pretende el dogma católico. En esa trayectoria, afirma Sor Juana: "Dios dio al hombre libre albedrío

\footnotetext{
${ }_{15}$ Cruz, Sor Juana Inés de la, Respuesta de la poetisa a la muy ilustre Sor Filotea de la Cruz, en: Polémica, op. cit., p. 79.

16 Cruz, Sor Juana Inés de la, Carta atenagórica, en: Polémica, op. cit., 62.
} 
con que puede querer y no querer obrar bien o mal, sin que para esto pueda padecer violencia, porque es homenaje que Dios le hizo y carta de libertad auténtica que le otorgó." ${ }^{17}$ Así pues, Dios guarda silencio, pues ¿qué sería del mundo si todo fuese palabra de Dios, si todo fuese sólo Logos divino?

En otras palabras, el Dios sorjuanino es un Dios que se retira de su propia creación, se reprime para que el ser humano pueda ser libre y tenga la posibilidad de ser lo que es. Entonces, el mayor beneficio negativo estriba en esa contención divina en la vida del hombre para que éste resuelva su propia condición y agote sus posibilidades racionales, que denotan la parte divina que hay en él.

Sin embargo, pese a que existe este vínculo con lo divino, el amor entre ambas esencias es imposible, pues el ser humano no puede amar más que como lo que es, por ello el primer mandamiento cristiano: "Amarás a Dios sobre todas las cosas", implica el sacrificio de la esencia humana, que es temporal y de carácter disonante.

Por otra parte, al ser innegablemente heredera de la tradición neoplatónica y escolástica — y como rasgo distintivo del ambiente barroco—, se valió de las obras de Kircher, ${ }^{18}$ quien consideró que el saber científico y la contemplación estética del cosmos era una sola e inseparable forma de conocimiento. De ahí que la Décima musa hiciera converger ideas y conceptos de la tradición aristotélico-tolomeica y del hermetismo neoplatónico, un quehacer por demás inusitado en aquel entonces. En sus composiciones, es innegable la aproximación que tiene a importantes cuestiones de índole física, metafísica y de filosofía del lenguaje, que más tarde serán objeto de análisis por otros célebres personajes de la filosofía y la ciencia. Basta con observar las alusiones que hace a problemas como el de la potencia, de la presencia bilocada y de la denominación extrínseca, donde se muestra, además, versada y cierta. ${ }^{19}$

En su juego conceptual, Sor Juana hace confluir tradiciones filosóficas contrarias, como el neoplatonismo, el hermetismo y la aristotélico-tomista que es más bien escolástica, con la finalidad de encontrar la metodología más adecuada para comprender el mundo natural y alcanzar un conocimiento verdadero. De aquí que los versos sorjuaninos puedan constituirse en un importante eje de reflexión filosófica y no sólo estilística o artística.

\footnotetext{
17 Ibid., p. 57.

${ }_{18}$ Kircher fue gran estudioso de la cultura egipcia y de los jeroglíficos y aseguraba que estos últimos debían leerse como símbolos y no como conceptos.

${ }_{19}$ Tan sólo algunos ejemplos de estos análisis se encuentran en el Romance intitulado: "Ya que para despedirme", donde la Fénix hace alusión al tema de la bilocación, vv. 73-75; otro más en: "Letras para cantar" vv. 1-8, donde apunta a cuestiones cosmológicas, objeto de la física moderna, y en otro lugar se refiere al problema de la significación, específicamente en: "Escribiendo a un caballero que decía tener el alma de nieve", vv.93-96, donde dice expresamente: "Varias denominaciones/ a una misma cosa hallamos,/ sin que la substancia inmute/ lo exterior de los vocablos (...)”.
} 
Para Sor Juana, el saber científico destaca también como experiencia estética y existencial, de modo que no es un saber aislado y de acceso exclusivo para cierto sector, pues también conviene reconocer que el desarrollo de la ciencia se ha nutrido del pensamiento simbólico, pues como afirma Elías Trabulse:

muchas de las más abstractas conquistas de las ciencias exactas — desde la física hasta la astronomía - tuvieron cono axioma fundamental [...] una forma de pensamiento simbólico por medio del cual se deseaba penetrar en los aspectos más profundos — que por ser tales escapaban a la observación científica - de la realidad, ya que estos aspectos desafiaban - y desafían - cualquier otra forma de conocimiento. ${ }^{20}$

En su afán por desvelar los misterios del mundo natural, Sor Juana utiliza la imagen del sueño para hacer que las inconstancias de la realidad permanezcan estáticas, pues para aquilatar el mundo y sus componentes es preciso que todo se encuentre en reposo, y así observar detalladamente lo que en ocurre en cada elemento natural para descubrir el misterio que pone en marcha a semejante orbe. ${ }^{21}$

En la epistemología sorjuanina, Dios está ausente en el acto mismo de conocer, en el modo de aprehensión de las cosas, de manera que sólo es una correlación entre el sujeto cognoscente y el objeto apuntado, lo cual, para su tiempo, implicó una osadía moral, pero también una provocación para el intelecto.

El Primero sueño es una experiencia personal y, por tanto, es posible darse cuenta de que su procedimiento es inverso al panteísmo, pues en éste el universo está lleno de Dios, mientras que para Sor Juana el universo está lleno del hombre, impregnado, por decirlo así, de humanidad, pues el mecanismo de todas las cosas es muy semejante al que se produce en los seres humanos.

En su simbología, la "piramidal funesta de la tierra" es una sillería que abre paso a una abisal sombra que oscurece las condiciones del universo y las formas recónditas que operan en la naturaleza. En ese tenor, la tiniebla de la ignorancia aprisiona al universo, y es menester de la luz del raciocinio verter su resplandor sobre todas las cosas con el fin de desvelarlas y mostrarlas tal cual son. Esto es una crítica a las formas canónicas de la comprensión del mundo en la Nueva España, pero también, y sobre todo, es una actitud que denota provocación.

20 Trabulse, Elías, “Sor Juana Inés de la Cruz y la ciencia perdida”, en: Peña, Margarita (comp.), op. cit., p. 21.

21 A partir del verso 210 del Primero sueño, la poetisa señala en varios momentos de su composición que el cuerpo juega un papel imprescindible en el ejercicio del conocimiento, con lo que presenta su tendencia aristotélica. Específicamente en el verso 252, Sor Juana confirma que el estómago: "templada hoguera del calor humano", envía los vapores de los cuatro humores: flema, bilis negra, bilis amarilla y sangre, que forman los llamados "simulacros" al sentido común, y éste a la imaginación para que después ésta los guarde en la memoria y puedan formarse múltiples imágenes, que posteriormente se puedan extraer en momentos determinados. Véase Cruz, Sor Juana Inés de la, Primero Sueño, pp. 500-502, versos 252-269, en: Obras completas I, Lírica personal, Antonio Alatorre (ed.), FCE, México, 2009. 
Cuando Sor Juana busca los métodos que le permitan alcanzar el conocimiento de las cosas, no piensa en derribar la "piramidal funesta de la tierra", sino coordinarla con la posición del sol, de modo que la sombra se aleje.

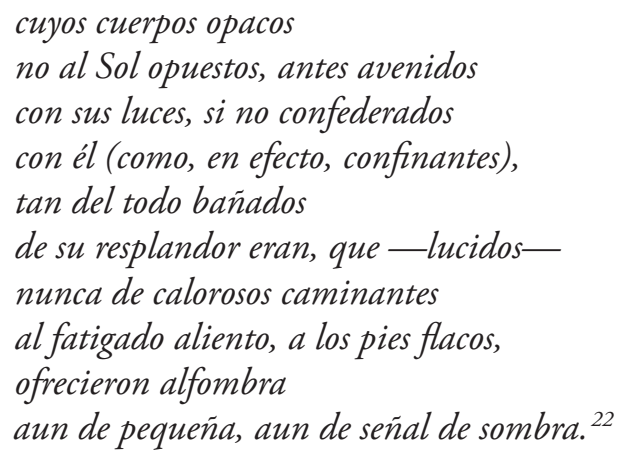

De aquí que la "piramidal funesta" no sea otra cosa más que el muro de los prejuicios, la conciencia ciega que ha de abrir sus ojos y llenarse poco a poco de luz.

Cuando la poetisa se percata de que la intuición no puede abracar la totalidad de las cosas, acude a una metodología conciliadora, y al darse cuenta de que este proceder tampoco es del todo eficaz — sin olvidar sus innegables provechos-, se siente doblegada con la próxima llegada del amanecer. Es este el momento en el que Sor Juana confirma las limitaciones humanas y, sin embargo, el deseo de saber no cesa. De ahí que Unamuno invierta las palabras de la Fénix de México y se atreva a sostener junto con ella: "Si es para saber tan poco, ¿¿de qué sirve vivir tanto?" 23

En este contexto, donde acaece la conciencia de un Todo y el anhelo que se percibe ineficaz al querer alcanzarlo, es posible decir que existe una hendidura emocional por la que se cuela la nostalgia, si entendemos que ésta surge ante la falta o la ausencia que se percibe en el fondo del alma y la invade cuando se separan realidad e idealidad. Pero justo en ese momento se traba un lazo que mantiene unidos a estos dos principios.

Mientras la Gracia me excita por elevarme a la esfera,

\footnotetext{
22 Cruz, Sor Juana Inés de la, Primero sueño, op. cit., versos 369-378, pp. 507-508.

${ }^{23}$ Unamuno, Miguel de, "Sor Juana Inés, hija de Eva" en: Obras completas $I V$, Escelicer, Madrid, 1971, pp. 1051-1053.
} 
más me abate a lo profundo

el peso de mis miserias. ${ }^{24}$

Esta expresión emotiva, que apela a las circunstancias, puede extrapolarse al terreno del conocimiento, pues no hay que olvidar que si el Primero sueño es la obra más personal de Sor Juana, y donde expone con prestancia que el mayor de sus amores es el "saber para ignorar menos", sin duda manifiesta también su sentir cuando se encuentra con la luz del día que le revela su natural demarcación.

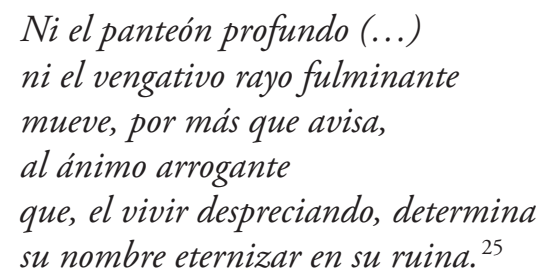

Y en otro lugar apunta:

Tan severo en mi contra has procedido, que me persuado, de tu duro intento, a que sólo me diste entendimiento porque fuese mi daño más crecido. ${ }^{26}$

Así pues, Sor Juana experimenta una caída que le revela un tiempo perdido, un “ipara qué vivir tanto?”. En ese sentido, el espíritu nostálgico acaece en la ruptura entre el deseo humano por alcanzar un fin y una realidad impenetrable que se lo impide, es también el sentimiento que ocurre en la exaltación nocturna de acostarse sin tener la esperanza del mañana.

\footnotetext{
${ }^{24}$ Cruz, Sor Juana Inés de la, “Mientras la Gracia me excita”, versos 1-4, en: Poesía lírica, José Carlos González Boixo (ed.), Cátedra, Madrid, 8a ed., 2009, p. 248.

25 Cruz, Sor Juana InÉs de la, Primero sueño, en: op. cit., versos 796-802, p. 531.

${ }^{26}$ Cruz, Sor Juana Inés de la, “'Tan grande, jay hado!, mi delito ha sido...?”, versos 5-8, en: Poesía lírica, op. cit., p. 255.
} 


\section{Referencias Bibliográficas}

Benítez, Laura, "Sor Juana Inés de la Cruz y la reflexión epistemológica en el Primero sueño", en: Peña, Margarita (comp.), Cuadernos de Sor Juana, Coordinación de Difusión Cultural UNAM, México, 1995.

Chávez, Ezequiel A., Ensayo de psicología de Sor Juana Inés de la Cruz y de estimación del sentido de su obra y de su vida para la historia de la cultura y de la formación de México, Editado por la Asociación Civil Ezequiel A. Chávez, México, 1972.

Cruz, Sor Juana Inés de la, Carta atenagórica, en: Polémica, Mirla Alcibíades (ed.), Biblioteca Ayacucho, Caracas, 2004.

- Sor Juana Inés de la, Poesía lírica, José Carlos González Boixo (ed.), Cátedra, 8 a edición, Madrid, 2009.

- Sor Juana Inés de la, Primero Sueño, en: Obras completas I, Lírica personal, Antonio Alatorre (ed.), FCE, México, 2009.

- Sor Juana Inés de la, Respuesta de la poetisa a la muy ilustre Sor Filotea de la Cruz, en: Polémica, Mirla Alcibíades (ed.), Biblioteca Ayacucho, Caracas, 2004.

Gallegos Rocafull, José María, El pensamiento mexicano en los siglos XVI y XVII, Ediciones del IV Centenario de la UNAM, México, 1951.

Glantz, Margo, "Prólogo”, en: Cruz, Sor Juana Inés de la, Obra selecta, Biblioteca Ayacucho, Caracas, 1994.

PAz, Octavio, Sor Juana Inés de la Cruz o las trampas de la fe, FCE, México, 1982.

Ruíz, Beatriz, "Una idea sobre el barroco en México", en: Peña, Margarita (comp.), Cuadernos de Sor Juana, Coordinación de Difusión Cultural UNAM, México, 1995.

Soriano Vallés, Alejandro, Aquella Fénix más rara, Nueva Imagen, $1^{\text {a }}$ edición, México, D.F., 2000.

Trabulse, Elías, La muerte de Sor Juana, Centro de Estudios de Historia de México, México, 1999.

— "Sor Juana Inés de la Cruz y la ciencia perdida”, en: Peña, Margarita (comp.), Cuadernos de Sor Juana, Coordinación de Difusión Cultural UNAM, México, 1995. 
Ugalde González, Rosalba, La filosofía del amor de Sor Juana Inés de la Cruz, Instituto Nacional de las Mujeres, 1a edición, México, D.F., 2009.

Unamuno, Miguel de, "Sor Juana Inés, hija de Eva" en: Obras completas IV, Escelicer, Madrid, 1971.

DOI: http://dx.doi.org/10.15366/bp2018.18.014

Bajo Palabra. II Época. No18. Pgs: 291-304 